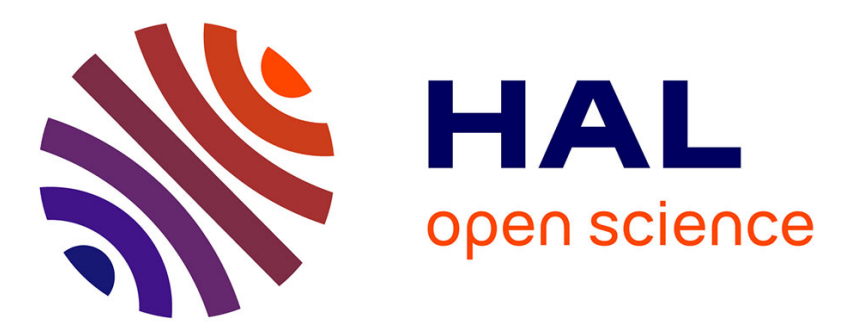

\title{
Atmospheric Velocity Spectral Width Measurements Using the Statistical Distribution of Pulsed CO2 Lidar Return Signal Intensities
}

\author{
Gérard Ancellet, Robert T. Menzies, William B. Grant
}

\section{- To cite this version:}

Gérard Ancellet, Robert T. Menzies, William B. Grant. Atmospheric Velocity Spectral Width Measurements Using the Statistical Distribution of Pulsed CO2 Lidar Return Signal Intensities. Journal of Atmospheric and Oceanic Technology, 1989, 6 (1), pp.50-58. 10.1175/1520-0426(1989)0062.0.CO;2 . hal-03124579

\author{
HAL Id: hal-03124579 \\ https://hal.science/hal-03124579
}

Submitted on 28 Jan 2021

HAL is a multi-disciplinary open access archive for the deposit and dissemination of scientific research documents, whether they are published or not. The documents may come from teaching and research institutions in France or abroad, or from public or private research centers.
L'archive ouverte pluridisciplinaire HAL, est destinée au dépôt et à la diffusion de documents scientifiques de niveau recherche, publiés ou non, émanant des établissements d'enseignement et de recherche français ou étrangers, des laboratoires publics ou privés. 


\title{
Atmospheric Velocity Spectral Width Measurements Using the Statistical Distribution of Pulsed $\mathrm{CO}_{2}$ Lidar Return Signal Intensities
}

\author{
Gerard M. ANCELlet, Robert T. MENZIES AND WILllaM B. GRANT \\ Jet Propulsion Laboratory, California Institute of Technology, Pasadena, California
}

(Manuscript received 19 October 1987, in final form 18 April 1988)

\section{ABSTRACT}

\begin{abstract}
A pulsed $\mathrm{CO}_{2}$ lidar with coherent detection has been used to measure the correlation time of backscatter from an ensemble of atmospheric aerosol particles which are illuminated by the pulsed radiation. The correlation time of the backscatter of the return signal, which is directly related to the velocity spectral width, can be used to study the velocity structure constant of atmospheric turbulence and wind shear. Various techniques for correlation time measurement are discussed, and several measurement results are presented for the technique using the information contained in the statistical distribution of a set of lidar return signal intensities.
\end{abstract}

\section{Introduction}

Extensive studies of atmospheric wind shear and wind velocity fluctuations have been performed using various instrumental techniques to deduce the kinematic structure of the lower troposphere in quiet and stormy weather. The two major spectral broadening mechanisms of Doppler lidar signals, due to the atmosphere itself, are wind shear and wind velocity fluctuations associated with turbulent motions. The shear term can be calculated from the range dependence of the first moment of the Doppler lidar spectrum. It can also be estimated from balloon radiosounding data, in which case one could then deduce the turbulence-related term after subtracting the contribution of the shear effect to the spectral width, providing instrumental effects are small (e.g., high laser frequency stability, suitably long transmitted pulse length). Although Doppler lidar techniques are restricted to clear air weather conditions, wind field measurements by airborne Doppler $\mathrm{CO}_{2}$ lidars have recently been demonstrated (Bilbro 1986; Woodfield and Vaughan 1983), offering new prospects for the use of mobile Doppler lidars in mesoscale investigations of the planetary boundary layer (PBL).

In this study, we discuss coherent lidar measurements of wind shear and velocity fluctuations. Although similar measurements can obviously be obtained using different wind profilers, e.g., VHF or microwave radars, or acoustic sounders (Strauch 1985; Balser and Netteville 1981), the coherent lidar has certain complementary properties. In the limit of the Kol-

Corresponding author address: Dr. Robert Menzies, Jet Propulsion Laboratory, California Institute of Technology, 4800 Oak Grove Drive, Pasadena, CA 91109. mogorov theory, all the statistical properties of atmospheric turbulence can be related to one parameter, $\epsilon$, the dissipation rate of the turbulent kinetic energy (Pasquill 1974). To relate $\epsilon$ to the Doppler spectrum width (after removal of the shear contribution), one must assume that the size of the largest eddies within the inertial range is larger than or approximately equal to the size of the lidar resolution volume (Doviak and $\mathrm{Zrnic}$ 1984). In many cases, this is an adequate assumption. The lidar probe volume has a shape similar to that of a pencil, with the largest dimension related to the pulse length. For a pulsed $\mathrm{CO}_{2}$ Doppler lidar the pulse length typically ranges from 1 to $3 \mu \mathrm{s}(\Delta R=150$ to $450 \mathrm{~m}$ ). New technological developments will soon lead to the possibility of equivalent measurements with a Nd:YAG coherent lidar, with pulse lengths almost an order of magnitude shorter, implying a range resolution $\Delta R=15-45 \mathrm{~m}$.

Feasibility studies of Doppler lidar performance for global wind measurements have assumed laser pulse lengths of 5-7 $\mu \mathrm{s}$ and a matched filter bandwidth (Huffaker 1985; Osmundson and Martin 1985); however, the optimum time window to calculate the power spectrum may be limited to smaller values by atmospheric effects. Turbulence and wind shear place a limitation on the temporal coherence of Doppler lidar returns in the visible and infrared wavelengths. These atmospheric effects should be assessed for various atmospheric conditions and at different altitude levels in the troposphere.

This paper presents atmospheric range-gated measurements of velocity spectrum width, using a ground based pulsed $\mathrm{CO}_{2}$ lidar, for various atmospheric conditions, making use of supporting standard meteorological data obtained from balloon radiosounding. In a previous paper (Ancellet and Menzies 1987) we in- 
dicated how measurements of the probability distribution function (PDF) of atmospheric backscatter lidar signal intensity leads to the velocity spectrum width, using the aerosol particles as tracers of atmospheric motion in the resolution volume. We discussed the measurements in terms of the temporal coherence of the Doppler lidar return signal. In this paper we present range-gated measurements and a more detailed analysis of the limiting factors associated with this measurement technique.

\section{The measurement technique}

\section{a. Measurement of the coherence time}

The received lidar signal arises from the backscatter of a distant volume element which contains aerosol particles moving with mean velocity equal to the bulk wind velocity. The PDF of an atmospheric backscatter coherent lidar signal intensity generally resembles an exponential density function, which is characteristic of a fully developed speckle pattern, but it changes to a $\mathrm{K}$ distribution when significant atmospheric turbulence is present (Gudimetla and Holmes 1982) or a modified Gamma distribution when time averaging (using a low pass filter at the receiver) is over periods longer than the coherence time of the signal (Parry 1975). The PDF is calculated from a set of several laser shots $(>100)$. Using the first and the second moments of the statistical distribution of the received intensity at a particular time (range), one calculates the ratio of the mean to the square root of the variance, referred to as the inverse relative root variance (IRRV), which is related to the carrier-to-noise ratio (CNR), the number of independent spatial modes detected at the receiver $\left(M_{A}\right)$, and the number of independent temporal coherence samples $\left(M_{T}\right)$ contained in the integration time (range bin) of the receiver (Shapiro et al. 1981):

$$
\mathrm{IRRV}=\left(\frac{\mathrm{CNR} / 2}{1+\mathrm{CNR} /\left(2 M_{A} M_{T}\right)+1 /(2 \mathrm{CNR})}\right)^{1 / 2}
$$

The CNR is the ratio of the mean signal power to the mean noise contribution. For CNR $\gg 5$, and $M_{A} \approx 1$ (i.e., only one spatial mode is detected). Eq. (1) becomes

$$
\text { IRRV }=\sqrt{M_{T}}\left(1+2 M_{T} / \mathrm{CNR}\right)^{-1 / 2} .
$$

These two conditions are generally applicable for measurement in the lower troposphere using a typical pulsed $\mathrm{CO}_{2}$ coherent lidar. Therefore the knowledge of the PDF leads to the number of independent temporal samples $M_{T}$.

Then one may express the number of coherent samples in the lidar range resolution element as

$$
M_{T}=1+2 /\left(B \tau_{c}\right) \text {, }
$$

where $B$ is the smallest full bandwidth of the receiver electronics and $\tau_{c}$ is the coherence time of the return signal. This equation is a direct result of the expression of measured current fluctuations in heterodyne detection, assuming that the photocurrent is a gaussian random variable and that the admittance of the (postdetection) low-pass filter has a Lorentzian shaped bandpass (e.g., an RC filter). The validity of the relation expressed in (3) has been proven by Fukuda et al. (1984), who recorded IRRV measurements in the boundary layer using a pulse duration $(\tau \leqslant 200 \mathrm{~ns})$ shorter than the expected atmospheric correlation time in the boundary layer and obtained a coherence time equal to the pulse length, using (3). We observed the same behavior when operating our $\mathrm{CO}_{2}$ lidar transmitter with short pulse durations. (These measurements are useful in proving the validity of (3), since they correspond to IRRV measurements in the case of a known coherence time, $\tau_{c}$, of the detected signal.)

When using a long laser pulse duration, i.e., larger than the atmospheric aerosol correlation time, $(\geqslant 3 \mu \mathrm{s})$, the coherence time of the backscatter signal is a function of velocity fluctuations or wind shear in the resolution element. Then $\tau_{c}$ is given by $\tau_{c}=1 /\left(2 k \sigma_{v}\right)$ (Churnside and Yura 1983) and (3) becomes

$$
M_{T}=1+4 k\left(\sigma_{t}+\sigma_{s}\right) / B
$$

where $k$ is the wavenumber; $\sigma_{t}$ and $\sigma_{s}$ are, respectively, the Doppler spectral width contributions due to the wind velocity fluctuations associated with turbulence and due to the wind shear, and $\sigma_{v}=\sigma_{t}+\sigma_{s}$.

\section{b. Instrumental and atmospheric decorrelation pro- cesses}

To derive (4) from (3), we neglected decorrelation processes that are not related to wind velocity fluctuations or wind shear within the resolution volume. Although they might be small, they have to be identified and assessed to determine the measurement accuracy. The transmitted pulse length is not the only parameter to influence the coherence time of the backscatter signal. It might also be limited by the existence of large gradients in the aerosol distribution within the resolution volume. One has to be concerned with this limitation when measurements at the top of the boundary layer are needed; this can be studied by transferring the aerosol backscatter variation in the resolution volume to an equivalent laser pulse envelope variation. Using a laser pulse modeled as a two-step function, which can satisfactorily represent a typical TEA $\mathrm{CO}_{2}$ laser pulse (e.g., a 200-ns narrow gain switched spike followed by a $2.8-\mu$ s tail containing $70 \%$ of the total energy), we calculated the combined effect of an aerosol distribution decay at the top of the boundary layer and of the $1 / R^{2}$ dependence of the lidar signal on the laser pulse envelope. We assumed that the lidar is probing a resolution element located at a $1-\mathrm{km}$ range from the lidar, viewing it at an angle of $30^{\circ}$ with respect to the horizontal. Both a ground based lidar $\left(+30^{\circ}\right.$ elevation $)$ and an airborne lidar $\left(-30^{\circ}\right.$ elevation) were considered 
because the aerosol distribution decay with increasing altitude will weight the results towards shorter ranges in the first case and towards longer ranges in the second case. In both cases, the $1 / R^{2}$ dependence will weight the results towards shorter ranges. Based on aerosol distributions presented in the next section, an aerosol vertical decay rate of $35 \mathrm{db} / \mathrm{km}$ in the resolution volume was assumed. The initial transmitted pulse and the two modified pulse envelopes are shown in Fig. 1. For a ground-based lidar, the relative importance of the narrow gain switched spike has been largely reduced. This leads to a small improvement in the coherence of the return signal. For an airborne lidar, the pulse envelope remains essentially identical to the initial pulse as a result of the two counteracting effects of aerosol distribution decay and the $1 / R^{2}$ dependence of the return (assuming $R$ approximately equal to $1 \mathrm{~km}$ ). [For this particular modeled laser pulse shape, the effect of the pulse envelope itself on the coherence time of the return signal was calculated in a previous paper (Ancellet and Menzies 1987) and found to be $2 \mu \mathrm{s}$, based on the calculated width of the signal autocovariance function.]

When turbulence is present along the path between the lidar and the volume element, the $\mathrm{K}$ distribution has been proposed by Gudimetla and Holmes (1982) as a reasonable approximation for the PDF of the lidar return intensity. They showed that, as the turbulence increases, the normalized variance of intensity rises above unity and reaches a peak value of approximately 1.25 at a Rytov variance, $\sigma_{x}^{2}$, of one tenth (for a wavelength of $0.48 \mu \mathrm{m}$ ). An expression for the IRRV was also proposed by Shapiro et al. (1981), for the propagation of a speckle field through a turbulent atmosphere. Assuming, for simplicity, $M_{A}$ and $M_{T}$ equal to unity and a nearly diffraction limited transmitted beam, this expression becomes

$$
\operatorname{IRRV}=\left(\frac{\mathrm{CNR}^{*} / 2}{1+\mathrm{CNR}^{*} / 2 A+1 /\left(2 \mathrm{CNR}^{*}\right)}\right)^{1 / 2}
$$

where $\mathrm{CNR}^{*}=\mathrm{CNR} \exp \left(4 \sigma_{x}^{2}\right)$ and $A=\exp -\left(16 \sigma_{x}^{2}\right)$. Considering daytime measurements at $10-\mu \mathrm{m}$ wavelength along a slant path (few degrees above the horizontal) at a range of $5 \mathrm{~km}$, one expects a Rytov variance of 0.01 . For high CNR values, this leads to IRRV $=0.92$. This corresponds to an equivalent velocity variance error of $3 \times 10^{-2} \mathrm{~m} \mathrm{~s}^{-1}$ for a $500-\mathrm{kHz}$ receiver bandwidth. Thus the effect of turbulence along the propagation path is negligible compared to other sources of error.

\section{c. Comparisons with other techniques}

A more direct way to measure the velocity spectrum width of the signal is to compute the signal spectrum itself for each shot. Obtaining an estimated width of the spectrum for each shot is a definite advantage compared to the IRRV technique, which requires the ac-

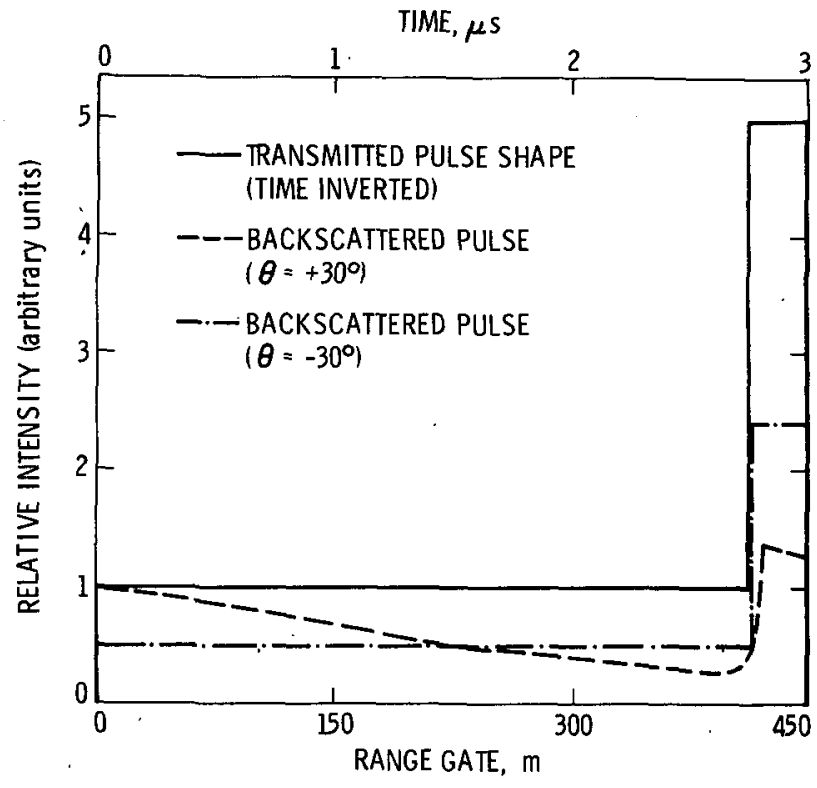

FIG. 1. Modification of the influence of the transmitted puise shape (modeled as a double-step function) on the backscatter contribution function, due to an aerosol gradient in the range gate at $1 \mathrm{~km}$ (as described in the text), for lidar elevation angles $\theta= \pm 30^{\circ}$.

quisition of several shots $(\sim 100)$ to obtain the PDF of the signal. This limitation might even be a serious problem when the advecting atmosphere is far from being stationary in a statistical sense. However, from experimental measurements of the aerosol structure function in the boundary layer, Post (1978) concluded that the spatial structure of atmospheric aerosols was in approximate steady state motion for observation times less than $30 \mathrm{~min}$. From our experimental observations of aerosol backscatter profiles resulting from 4-min averaging times (and with a $150-\mathrm{m}$ spatial resolution), we also concluded that the mean aerosol backscatter value in each resolution volume usually varies by less than $10 \%-15 \%$ during a 20 -min period. (See section 3.b.)

The major disadvantage of a direct measurement of the spectrum lies in the difficulty of removing the effect of the spectral processing itself. The two most common ways to estimate moments of the signal spectrum are based on the use of a Fast Fourier Transform algorithm or a poly-pulse-pair processor where the signal is converted from an analog signal to a digital sample and then subjected to autocovariance or spectral processing to produce the first three moments (Hardesty et al. 1983). The finite time window associated with the discrete nature of the spectrum will produce a velocity spectrum width; e.g., for a sampling frequency of 50 $\mathrm{MHz}$ and a time window of $2.5 \mu$ s the width can be as large as $6 \mathrm{~m} \mathrm{~s}^{-1}$ when the mean frequency falls between two adjacent discrete frequency bands, the bias of the estimated mean remaining less than $0.5 \mathrm{~m} \mathrm{~s}^{-1}$ (Ancellet and Menzies 1987). This effect could be corrected pro- 
vided that the mean frequency is accurately known; unfortunately this is not usually the case. Because of the relatively small bias of the estimated mean frequency, one could alternately use the statistical fluctuations of the mean frequency to compute $\sigma_{v}$ by recording a set of several spectra. However, as is true for the IRRV technique, there may be a limitation due to the length of the observation time; the motions of the aerosol inhomogeneities with large spatial scales $(>500$ $\mathrm{m}$ ) would contribute to the broadening of the spectrum, reducing the ability to relate velocity spectral width to purely turbulent motions. This method is also sensitive to interpulse frequency jitter, in contrast to the IRRV method.

\section{Experimental data}

In this section, we will present the field measurements that were made at JPL, Pasadena, CA, using a pulsed coherent $\mathrm{CO}_{2}$ lidar system operating at the 10P(20) laser line $(10.59 \mu \mathrm{m})$ which provides the strongest return for boundary layer study. The experimental setup and data processing scheme were described in earlier publications (Ancellet and Menzies 1987; Menzies et al. 1984). Before recording data, we verified the intrapulse frequency stability of the TEA $\mathrm{CO}_{2}$ laser by adjusting the cavity alignment so that consistent and reliable transverse mode selection could be obtained. [Occasionally, poor transverse mode discrimination has been proven to be the main factor limiting the laser intrapulse frequency stability (Ancellet et al. 1987).] This precaution is taken to be sure that the velocity spectral resolution is limited only by the transform-limited laser pulse duration. For small velocity spectrum width $\left(<1 \mathrm{~m} \mathrm{~s}^{-1}\right)$, an attempt to remove the nonnegligible influence of the laser pulse $0.3 \mathrm{~m}$ $\mathrm{s}^{-1}$ ) has been made for the data presented in this section by deconvolution. Both spectra in this case were modeled as Gaussian, admittedly a coarse approximation for the pulse spectrum. This assumption affects mea- surements of velocity spectral width less than $0.5 \mathrm{~m}$ $\mathrm{s}^{-1}$. This could be considered as a detection limit.

\section{a. Planetary boundary layer (PBL)}

First we conducted several measurements of the IRRV at a given range of $1.5 \mathrm{~km}$ along a nearly horizontal path. (Results are summarized in Table 1.) Measurements in the PBL along a horizontal path are not dependent on vertical wind shear and are, therefore, representative only of turbulence level encountered in the PBL. The lidar was located on a hillside at an altitude of $450 \mathrm{~m}$ above sea level, and a range of $1.5 \mathrm{~km}$ along a horizontal path corresponded to an altitude of $80 \mathrm{~m}$ above the ground. We recorded sets of successive aerosol return signals under various atmospheric conditions. On two occasions, we also used different bandwidths and recorded two or three successive sets of data in order to verify experimentally the sensitivity of the method. The differences between those data (which are representative of the same turbulence conditions) are very small $\left(\sim 0.1 \mathrm{~m} \mathrm{~s}^{-1}\right)$ when converted to velocity spectral width. The values obtained for the various days are all about $0.5 \mathrm{~m} \mathrm{~s}^{-1}$ except on 22 January 1986 , where very low values were recorded. This day was characterized by very low visibility $(<2 \mathrm{~km})$, associated with stable conditions which contributed to a significant haze over the Los Angeles Basin, and by a cloudy sky, which reduced the thermal convection usually observed during the daytime. The concurrence of those two factors seems to have reduced the turbulence to a level such that very little spreading of the velocity spectrum was observed. It is interesting to compute the dissipation rate of the turbulent energy using a value of 0.5 $\mathrm{m} \mathrm{s}^{-1}$ for $\sigma_{v}$. Assuming a Kolmogorov spectrum (Tatarski 1971$)$, the power spectral density $S(k)$ is related to $\epsilon$ at the wavenumber $k$ :

$$
S(k)=A \epsilon^{2 / 3} k^{-5 / 3}
$$

where $A \approx 0.5$ (MacCready 1964 ; Gossard et al. 1984). By integrating the spectrum for the wavenumbers larger

TABLE 1. Observations along a horizontal path in the PBL.

\begin{tabular}{|c|c|c|c|c|c|c|}
\hline Date & $\begin{array}{l}\text { Time } \\
\text { (LST) }\end{array}$ & IRRV & $\begin{array}{c}B \\
(\mathrm{kHz})\end{array}$ & $\begin{array}{c}\sigma_{v} \\
\left(\mathrm{~m} \mathrm{~s}^{-1}\right)\end{array}$ & $\begin{array}{c}\text { Range } \\
(\mathrm{km})\end{array}$ & Meteorological observations \\
\hline \multirow[t]{2}{*}{17 Oct 85} & 1530 & 1.92 & 500 & 0.51 & 1.35 & PBL visibility $=6 \mathrm{~km}$ \\
\hline & 1630 & 2.38 & 200 & 0.41 & 1.35 & Partly cloudy sky, $T=20.8^{\circ} \mathrm{C}$ \\
\hline 21 Oct 85 & 1030 & 1.85 & 500 & 0.46 & 1.35 & $\begin{array}{l}\text { PBL visibility }=4 \mathrm{~km} \text {, cloudy } \\
\text { sky; rain at } 12: 00 \\
T=16.4^{\circ} \mathrm{C}\end{array}$ \\
\hline \multirow[t]{3}{*}{22 Oct 85} & 1515 & 2.94 & 100 & 0.31 & 1.2 & PBL visibility $=5 \mathrm{~km}$, hazy, \\
\hline & 1545 & 1.79 & 500 & 0.42 & 1.2 & clear sky above \\
\hline & 1615 & 2.78 & 100 & 0.27 & 1.2 & \\
\hline $22 \operatorname{Jan} 86$ & 1600 & 1.05 & 500 & $<0.1$ & 1.5 & $\begin{array}{l}\text { PBL visibility }=2 \mathrm{~km} \text {, foggy, } \\
\text { cloudy sky. } \\
T=18.1^{\circ} \mathrm{C}\end{array}$ \\
\hline $24 \operatorname{Jan} 86$ & 1000 & 1.74 & 500 & 0.39 & 1.4 & $\begin{array}{c}\text { PBL visibility }=4 \mathrm{~km} \text {, clear sky } \\
T=21.8^{\circ} \mathrm{C}\end{array}$ \\
\hline
\end{tabular}


than $1 / L$ where $L$ is the length of the resolution volume, one obtains a $\sigma_{v}$ that in turn can be used to derive $\epsilon$

$$
\epsilon=\frac{\sigma_{v}^{3}}{L} \cdot(3 A)^{-3 / 2} \text {. }
$$

We obtained a value of $9.3 \times 10^{-4} \mathrm{~m}^{2} \mathrm{~s}^{-3}$, which corresponds to a light to moderate turbulence regime according to the turbulence intensity scale defined by MacCready. Comparison with $C_{n}^{2}$ is rather difficult since $C_{n}^{2}$ is not only related to $\epsilon$ but also to $N$, which is the analog of $\epsilon$ for the temperature field fluctuations:

$$
\begin{aligned}
& C_{n}^{2}=\left(\frac{\left(8 \times 10^{-5}\right) p}{T^{2}}\right)^{2} C_{T}^{2} \\
& C_{T}^{2}=\frac{B N}{\epsilon^{1 / 3}}
\end{aligned}
$$

where $B$ is a numerical constant of the order of unity, and $p$ and $T$ are the pressure and temperature fields. However, as pointed out by Tatarski, a relation exists between $\epsilon$ and $N$ in the case of free convection, since both can be expressed in terms of the temperature flux. From these one obtains an equation for $C_{n}^{2}$ as a function of $\epsilon$ (independent of altitude in this case) and the altitude $z$ :

$$
C_{n}^{2}=0.7\left(\frac{\left(8 \times 10^{-5}\right) p}{g T}\right)^{2}\left(\frac{\epsilon}{z}\right)^{4 / 3}
$$

Using a value of $9.3 \times 10^{-4} \mathrm{~m}^{2} \mathrm{~s}^{-3}$ for $\epsilon$ and an altitude of two meters above ground, we obtain a $C_{n}^{2}$ value of $2.0 \times 10^{-13} \mathrm{~m}^{-2 / 3}$, assuming the measurements are representative of free convection conditions. This value is typical of what we expect for daytime conditions with clear sky. It is, therefore, encouraging that our estimation of turbulence levels based on velocity spectrum width measurements compared well with other estimates of the turbulence in the PBL during the daytime.

\section{b. Interface $P B L /$ free troposphere}

\section{1) The data COLlection}

After the investigations of the velocity spectrum width in the boundary layer, we focused our attention on the top of the PBL, because this is a zone of transition where we generally should observe variations in the turbulence or wind shear regime when scanning through that region. Using data obtained along a short path, we probed the top of the PBL with a vertical resolution of $\Delta z \approx 200 \mathrm{~m}$. The measurement dates and related information are in Table 2 . For all cases except 22 July 1986 , we also recorded a profile of the aerosol backscatter coefficient, $\beta$, along the line of sight in order to calculate the height of the PBL or to characterize the possible existence of successive aerosol layers rather than a well-defined and uniform PBL. (The uncertainty in the absolute accuracy of the $\beta$ values presented in this paper is approximately $\pm 6 \mathrm{~dB}$ ). On two days we also compared our measurements with balloon radiosondes which were launched $200 \mathrm{~m}$ south of the lidar location. They provided vertical profiles of temperature, relative humidity, and pressure. At the same time the vertical profiles of velocity and direction of the horizontal wind were also obtained by tracking the balloon with a theodolite. On 17 January 1986, we made two measurements of $\sigma_{v}$ in a single range gate but with two different elevation angles (measured from a horizontal plane). The two measurements were separated in time by $30 \mathrm{~min}$ and corresponded to two different altitudes. As shown by the two aerosol backscatter profiles (Fig. 2) recorded in 15-min intervals near 4:00 pm and 5:00 pm, the PBL was growing on that day with a vertical speed of $10 \mathrm{~cm} \mathrm{~s}^{-1}$; therefore, the first measurement was characteristic of the atmosphere $300 \mathrm{~m}$ above the PBL, and the second one of the top of the PBL. The contrast between the two $\sigma_{v}$ values obtained is a good indication of the level of dynamic activity that takes place at the top of the PBL in terms of turbulence and wind shear.

For the last three dates reported in Table 2, we recorded $\sigma_{v}$ measurements in successive range-gates to obtain a profile of $\sigma_{v}$ in an approximately $1-\mathrm{km}$ thick atmospheric layer with 100-m altitude resolution. The three profiles are displayed in Fig. 3.

\section{2) LARGE SCALE AEROSOL MOTION}

On 6 February 1987, we obtained the aerosol backscatter profiles using another $\mathrm{CO}_{2}$ coherent lidar system, located next to the lidar used for $\sigma_{v}$ measurements, and usually devoted to DIAL measurements in the PBL

TABLE 2. Profiles of $\sigma_{v}$ at the top of the boundary layer.

\begin{tabular}{lccccc}
\hline \hline Date & $\begin{array}{c}\text { Time } \\
(\text { LST })\end{array}$ & $\begin{array}{c}\text { Azimuth angle } \\
\left({ }^{\circ}\right)\end{array}$ & $\begin{array}{c}\text { Elevation angle } \\
\left({ }^{\circ}\right)\end{array}$ & $\begin{array}{c}\text { Aerosol backscatter } \\
\text { profile }\end{array}$ & $\begin{array}{c}\text { Meteorological } \\
\text { radiosounding }\end{array}$ \\
\hline 17 Jan 86 & 1615 & 180 & 14 & yes & no \\
& 1645 & 180 & 26 & yes & no \\
22 Jan 86 & 1400 & 180 & 40 & no & yo \\
4 Aug 86 & 1530 & 180 & 40 & yes & yes \\
6 Feb 87 & 1345 & 180 & 30 & yes* & yes \\
\hline
\end{tabular}

* Backscatter data were recorded with another lidar, described by Grant et al. (1987). See text for further description. 


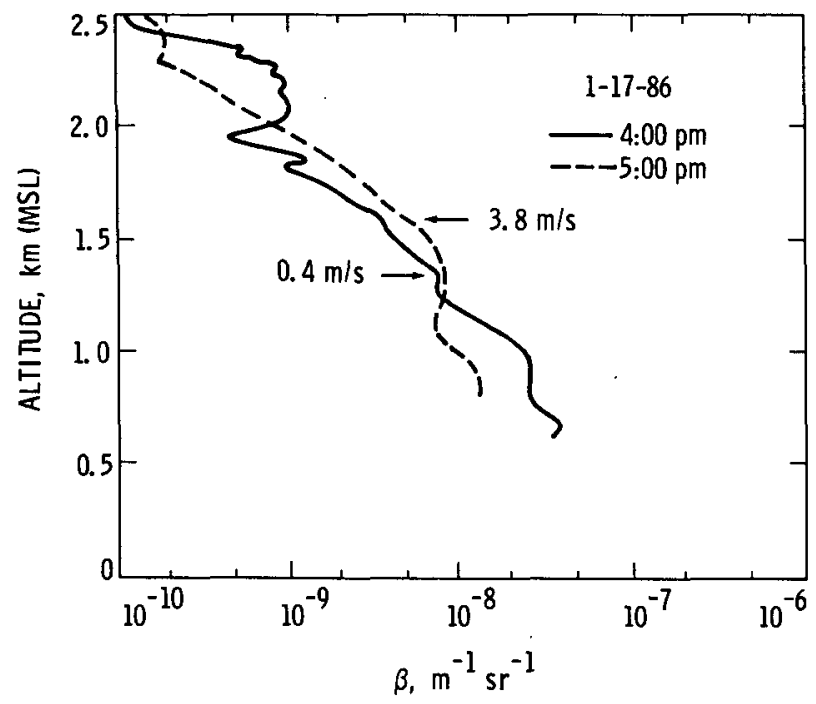

FIG. 2. Aerosol backscatter vertical profiles and corresponding velocity spectral width measurements at the indicated altitudes.

(Grant et al. 1987). This provided the advantage of simultaneous measurements of $\sigma_{v}$ and of the aerosol backscatter profile. Higher temporal and spatial resolution could be attained with this system, which has a typical pulse repetition frequency (prf) of $25 \mathrm{~Hz}$ and transmits pulses with 300-ns duration. A first set of three profiles and a second set of four profiles were recorded, using for each individual profile an acquisition time of $5 \mathrm{~min}$ and an altitude resolution of 75 $\mathrm{m}$. The first and the last profile, separated by $45 \mathrm{~min}$, are displayed in Fig. 4, showing substantial differences in the free troposphere and also in the PBL, the altitude of which was about $2 \mathrm{~km}$. We also plotted the time series of the aerosol backscatter measured at various altitudes (Fig. 5) in order to determine the observation time for which the atmosphere can be safely assumed as stationary. Within the PBL or at the transition between the PBL and the free troposphere, it is not un-

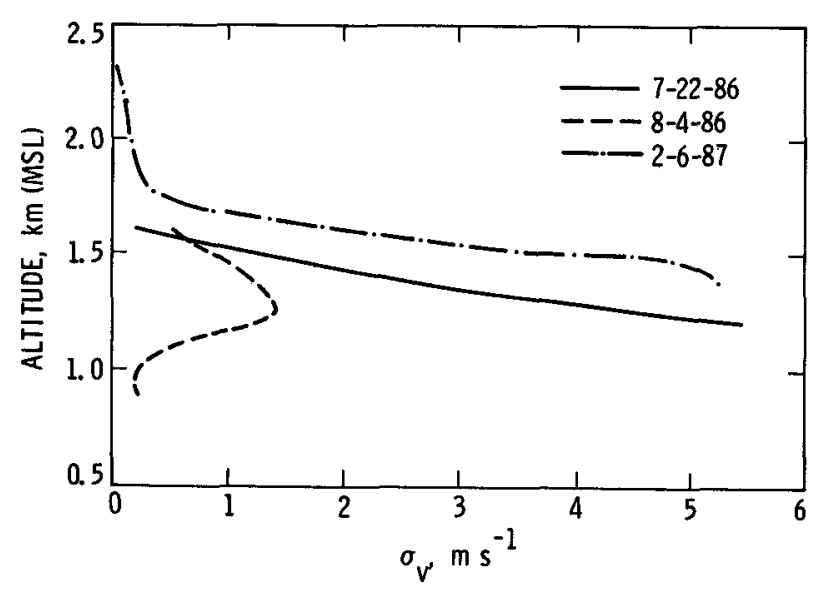

FIG. 3. Velocity spectral width vertical profiles.

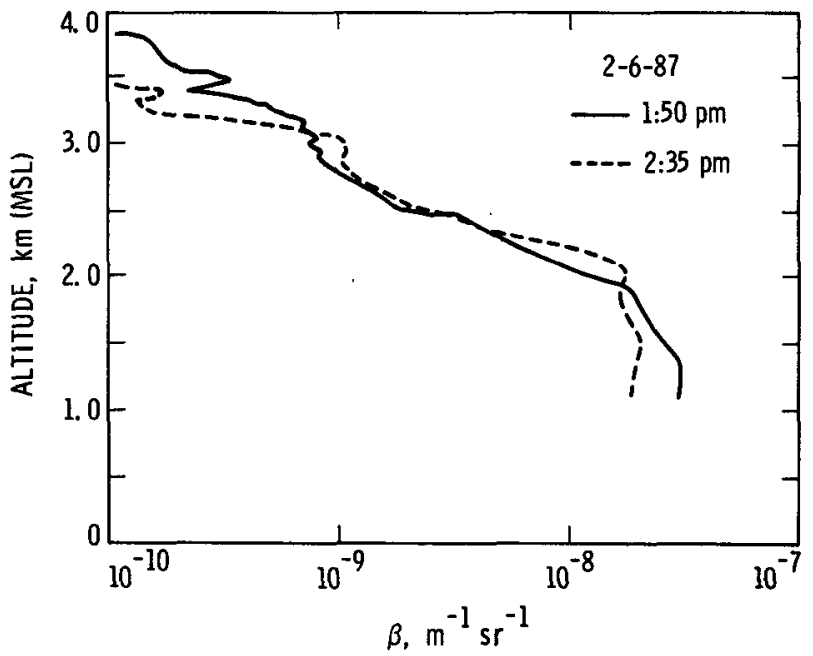

FIG. 4. Aerosol backscatter vertical profiles measured using MAPM.

reasonable to use an observation time of 20 or $30 \mathrm{~min}$ but it is clearly not the case at altitudes above $2.8 \mathrm{~km}$. It should be mentioned that a lidar system combining high PRF, high energy and long pulse duration could perform both $\sigma_{v}$ and aerosol backscatter measurements.

\section{3) Discussion}

On 22 July 1986 , high values of $\sigma_{v}\left(\geqslant 5 \mathrm{~m} \mathrm{~s}^{-1}\right)$ were obtained at an altitude which seems to be the top of the PBL, based on an analysis of the mean values of the atmospheric returns recorded in the successive

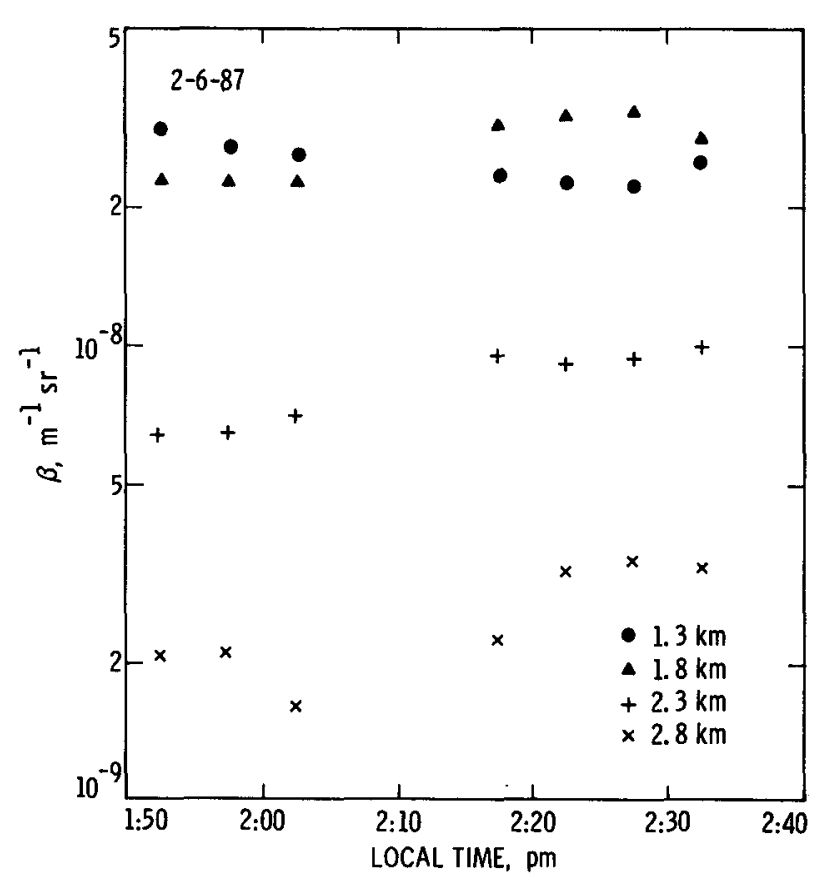

FIG. 5. Temporal variations of 5-min averaged aerosol backscatter at indicated altitudes. 
range gates. Because no supporting meteorological information was available on that day, we can only make conjectures about the mechanisms which produced such high values. One explanation might be the existence of a strong vertical wind shear of about $2 \times 10^{-2}$ $\mathrm{s}^{-1}$ aligned with the direction of the lidar. The turbulence generated by the existence of a wind shear might also combine with the direct broadening effect of the shear to produce a spectral width as large as $5.5 \mathrm{~m} \mathrm{~s}^{-1}$.

On 4 August 1986, the aerosol backscatter profiles (Fig. 6) reveal the existence of a $1.5-\mathrm{km}$ thick homogeneous aerosol layer superposed on a thin haze layer close to the ground and fairly stable, as indicated by the small differences between the two profiles. The radiosonde data indicate an inversion layer between 0.9 $\mathrm{km}$ and $1.4 \mathrm{~km}$ (Fig. 7) and also a very strong wind shear of about $2 \times 10^{-2} \mathrm{~s}^{-1}$ between $1 \mathrm{~km}$ and $1.5 \mathrm{~km}$. However, because a westerly wind regime was predominant at that altitude, the contribution to the velocity spectrum broadening remains small except between $1.1 \mathrm{~km}$ and $1.3 \mathrm{~km}$, where the wind direction was slightly northwest, and where the vertical shear of $1.4 \times 10^{-2} \mathrm{~s}^{-1}$ in the southerly component of the wind (Fig. 8) contributed to a $\sigma_{s}$ (the wind shear component) value of $1.4 \mathrm{~m} \mathrm{~s}^{-1}$, comparable to that obtained for $\sigma_{v}$. No obvious effect of the turbulence induced by the wind shear can be deduced from this profile, and this appears consistent with Richardson number values larger than 0.2 near $1 \mathrm{~km}$, which indicate that the turbulent motions associated with the wind shear were probably inhibited by the existence of the inversion layer at the same altitude.

On 6 February 1987, the velocity spectral width measurements corresponding to an observation time smaller than $30 \mathrm{~min}$ are quite similar to those obtained on 22 July 1986 . However, near $1.5 \mathrm{~km}$, the contri-

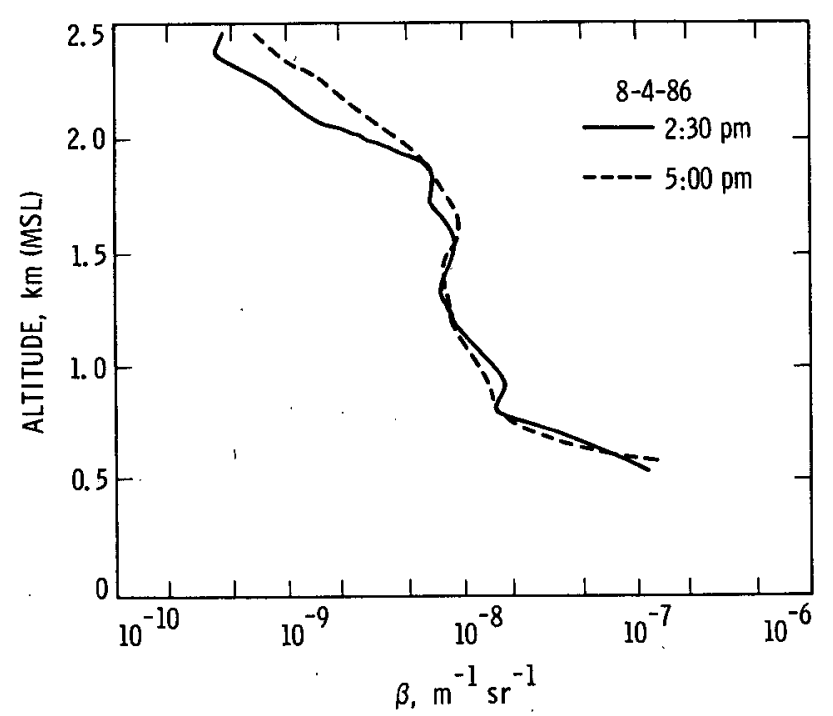

FIG. 6. Aerosol backscatter vertical profiles.
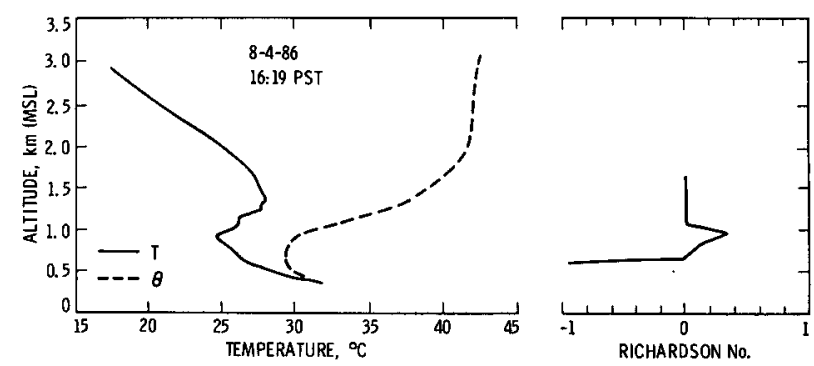

FIG. 7. Dry temperature $(T)$ and potential temperature $(\Theta)$ versus altitude, from radiosonde measurements. The Richardson number profile is indicated within the inversion layer.

bution of a shear in the north-south component of the wind accounts for a spectral broadening of only $1 \mathrm{~m}$ $\mathrm{s}^{-1}$ as a result of a moderate wind shear amplitude of $1.1 \times 10^{-2} \mathrm{~s}^{-1}$ (Fig. 9). Consequently the high $\sigma_{v}$ values recorded just below the top of the PBL do not seem related solely to the existence of a wind shear. Rather large turbulence conditions might have been encountered near the top of the PBL and at the bottom of the shear, considering the temperature lapse rate of -8.3 $\mathrm{K} \mathrm{km}^{-1}$ existing on that day (Fig. 10), characteristic of a moderately unstable atmosphere. Nevertheless, this would produce a $\sigma_{v}$ value of only $1.5 \mathrm{~m} \mathrm{~s}^{-1}$, assuming a dissipation rate of $9 \times 10^{-2} \mathrm{~m}^{2} \mathrm{~s}^{-3}$ and a resolution volume length of $450 \mathrm{~m}$. Therefore, the maximum expected value for $\sigma_{v}$ at $1.5 \mathrm{~km}$ would be $2.5 \mathrm{~m} \mathrm{~s}^{-1}$, a factor of two less than that obtained. The reason of this discrepancy is not clear. One reason might be related to inadequate vertical resolution in the wind velocity measurement, which was obtained by a somewhat coarse method (i.e., visual tracking of a balloon using a theodolite). The existence of a large vertical shear of the horizontal wind in a layer of $100 \mathrm{~m}$ thickness or less would be difficult to detect using this technique. However, such a shear would strongly influence the velocity spectral width measured by the lidar.

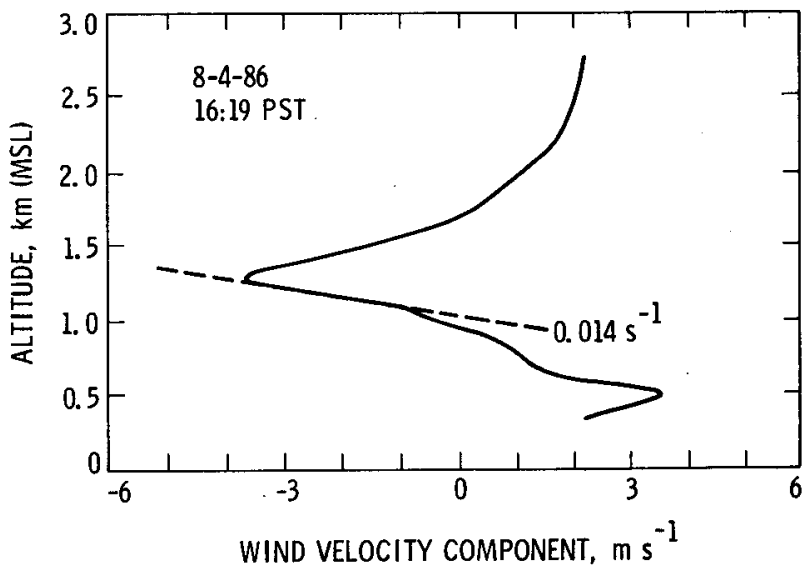

FIG. 8. Wind horizontal component aligned with the lidar direction, deduced from balloon tracking. 


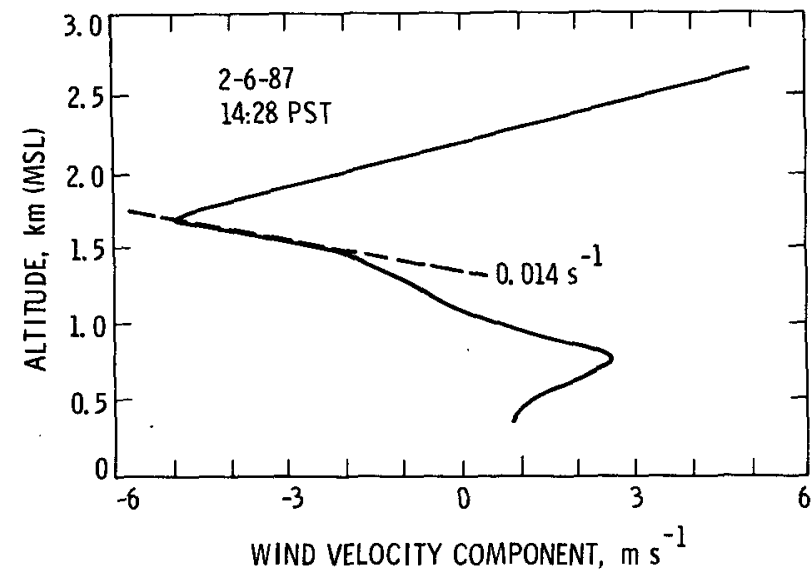

FIG. 9. Wind horizontal component along the lidar azimuth, deduced from balloon visual tracking.

\section{Conclusion}

We have described an investigation of a new method for measurement of the velocity spectrum width in the lower troposphere. Instead of relying on a direct measurement of the width of the spectrum, which generally requires discrete spectral processing or discrete autocovariance processing, our method makes use of the statistical distribution of the backscatter lidar signal in order to compute the inverse relative root variance (IRRV). Although the observation time for this technique is longer than for the direct measurement, no spectral processing is needed. Therefore, we avoid the broadening of the spectrum by the processing itself, which is often difficult to determine when using coherent Doppler lidar.

The experimental data, obtained using $\mathrm{CO}_{2}$ coherent lidar at $10-\mu \mathrm{m}$ wavelength, demonstrated the potential of this method for investigations of wind shear and/or turbulence in the planetary boundary layer (PBL). Turbulence strength values $C_{n}^{2}$, deduced from wind velocity variance measurements in the lidar resolution

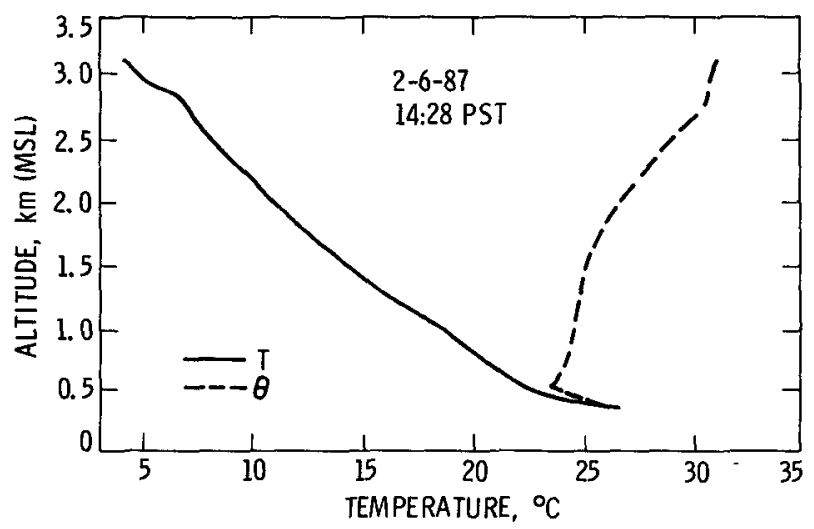

FIG. 10. Dry temperature $(T)$ and potential temperature $(\Theta)$ versus altitude, from radiosonde measurements. volume within the PBL, compared well with expected values for the weather conditions reported in Table 1. The lidar was also used to record profiles of the velocity spectrum width across the transition zone between the PBL and the free troposphere. For the two cases where visual balloon tracking provided wind velocities and directions, the spectrum broadening was shown to be related to the existence of wind shears near the top of the PBL. Values as large as $5 \mathrm{~m} \mathrm{~s}^{-1}$ are likely to be the result of a combined effect of wind shear within the resolution volume and of turbulence generated by the existence of the shear. Investigations such as these are encouraging for further use of this method to obtain more information about the mechanisms responsible for velocity spectrum broadening. However, to be able to separate more accurately the wind shear contribution from the turbulence contribution, better estimates of the wind velocities and directions must be obtained using either the Doppler information contained in the lidar signal itself or in situ measurements.

Acknowledgments. The authors would like to acknowledge S. Dermenjian for his technical support and A. Brothers for contributions to the data processing. During the period of this research, $G$. Ancellet was a National Aeronautics and Space Administration-National Research Council Resident Research Associate. $\mathrm{He}$ is now at the CNRS Service d'Aeronomie, Verrieres le Buisson, France. The research described in this paper was carried out by the Jet Propulsion Laboratory, California Institute of Technology, under contract with NASA.

\section{REFERENCES}

Ancellet, G. M., and R. T. Menzies, 1987: Atmospheric correlation time measurements and effects on coherent Doppler lidar. $J$. Opt. Soc. Am., A, 2, 367-373.

__ __ and A. M. Brothers, 1987: Frequency stabilization and transverse mode discrimination in injection-seeded unstable resonator TEA $\mathrm{CO}_{2}$ lasers. Appl. Phys., B., 44, 29-35.

Balser, M., and D. Netteville, 1981: Measuring wind turbulence with Doppler acoustic radar. J. Appl. Meteor, 20, 27-35.

Bilbro, J. W., C. DiMarzio, D. Fitzjarrald, S. Johnson and W. Jones, 1986: Airborne Doppler lidar measurements. Appl. Opt., 21, 3952-3960.

Churnside, J. H., and H. T. Yura, 1983: Speckle statistics of atmospheric backscattered laser light. Appl. Opt., 17, 2559-2565.

Doviak, R. J., and D. Zrnic, 1984: Doppler Radar and Weather $O b$ servations. Academic Press, 354 pp.

Fukuda, T., Y. Matsuura and T. Mori, 1984: Sensitivity of coherent range resolved differential absorption lidar. Appl. Opt., 23, 20262032.

Gossard, E. E., B. Russel, B. Chadwick, T. R. Detman and J. Gaynor, 1984: Capability of surface clear-air Doppler radar for monitoring meteorological structure of elevated layers. J. Climate Appl. Meteor., 3, 474-485.

Grant, W. B., J. S. Margolis, A. M. Brothers and D. M. Tratt, 1987: $\mathrm{CO}_{2}$ DIAL measurements of water vapor. Appl. Optics, 26, 30333042.

Gudimetla, V. S. R., and J. F. Holmes, 1982: Probability density function of the intensity for a laser-generated speckle field after propagation through the turbulent atmosphere. J. Opt. Soc. Am., 9, 1213-1218. 
Hardesty, R. M., R. W. Lee and D. L. Davis, 1983: Real time processing and display of coherent lidar returns. Technical Digest, 2nd Topical Meeting on Coherent Laser Radar, Aspen, WA21-WA2-4.

Huffaker, M., 1985: The Wind-Sat concept for measuring the global wind field. Proc. of the NASA Symposium on Global Wind Measurements, Deepak, 215-222.

MacCready, P. B., 1964: Standardization of gustiness values from aircraft. J. Appl. Meteor., 3, 439-449.

Menzies, R. T., M. Kavaya, P. H. Flamant and D. A. Haner, 1984: Atmospheric aerosol backscatter measurements using a tunable coherent $\mathrm{CO}_{2}$ lidar. Appl. Opt., 15, 2510-2517.

Osmundson, J. S., and S. C. Martin, 1985: Lockheed design of wind satellite (Wind Sat) experiment. Proc. of the NASA Symposium on Global Wind Measurements, Deepak, 195-200.

Parry, G., 1975: Speckle patterns in partially coherent light. Laser
Speckle and Related Phenomena, J. C. Dainty, Ed., SpringerVerlag.

Pasquill, F., 1974: Atmospheric Diffusion. John Wiley \& Sons, p. 51. Post, M. J., 1978: Experimental measurements of atmospheric aerosol inhomogeneities. Opt. Lett., 6, 166-168.

Shapiro, J. H., B. A. Capron and R. C. Harney, 1981: Imaging and target detection with a heterodyne reception optical radar. Appl. Opt., 19, 3292-3313.

Strauch, R. G., 1985: Radar Wind Profilers. Proc. of the NASA Symposium on Global Wind Measurements, Deepak, 133-137.

Tatarski, V. I., 1971: The Effects of Turbulent Atmosphere on Wave Propagation. (Translated from Russian; Israel Program for Scientific Translations), Rep. \#TT-68-50464, National Scientific Foundation, Washington, DC.

Woodfield, A. A., and J. M. Vaughan, 1983: Airspeed and wind shear measurements with an airborne $\mathrm{CO}_{2} \mathrm{CW}$ laser. Int. $J$. Aviation Safety, 1, 207-224. 